\title{
The Culture Developing of China with Science and Technology in the Background of Western Culture
}

\author{
Jing-ze SUN \\ Science and technology of photo-electronic information college, university of Yantai, \\ Yantai, Shandong, China \\ Email: jsun@ytu.edu.cn
}

Keywords: Gem-stone, Taoism, Silicon, Carbon, Value, Virtue, Quantum, Electronics.

\begin{abstract}
Through review and comparison of the properties of gold and jade, as well as the tradition of their usage, the culture difference between the West and China is discussed from the aspect of illuminating their impact on civilization as gem-stones and the related. Further, the developing of Chinese culture is discussed on this basis, and the importance of understanding the quantum essence is discussed from the aspect that the importance of silicon and carbon to mankind life should be understood not only from scientific view as crucial materials to industry and economics, but also as inspiration and enlightenment for reflection of humanity, such as Chinese ancient philosophies. Therefore meditations and studies of the principles of value and virtue together with the quantum essence of these key materials are important ways to avoid oversight and ignorance and thereby conflicts in shaping and developing mankind modern civilization.
\end{abstract}

\section{Introduction}

After Chinese government established the graduate colleges, the developing of science and technology is extremely fast, especially with the impact of abroad studying and exchange policy. The history of modern science and technology in China is not very long, though China had had important and eminent contributions to human civilization, for example compass, printing technology, abacus and medicine, etc. With this background the dialogue and conflict between China and western world have an important force to the developing of both cultures.

Chinese culture is eminent and unique in human world, its characteristic is famous as harmony and peace under the long development with its ancient philosophies such as Taoism and Confucianism, as well as religion Buddhism. As well known Chinese scholars in the past had a different way to understand universe and world, therefore their pursuit can lead to recluse and ultimately become immortal. Today after education is westernized, Chinese scholars engage to pursue the true value of Chinese culture to establish modern Chinese characteristics by re-interpretation of ancient philosophy and dialogue with the West in various aspects including religion. As we can see that Chinese culture is having energetic impression with economic prosperity, such as population flowing, over-working phenomenon and fast social popularity, etc. Many such conflicts can lead to social unrest and instability. However because of the harmonic and peaceful characteristic tradition in Chinese culture, dedication to further and modernize this tradition is certainly a task.

As science, as well as technology, is an important factor of culture shaping, author as a physicist would like to discuss two economic valuable substances, i.e. gold and jade, 
to deliver a way to understand the culture difference between China and the West. Hence author proposes an enhancement in studying and teaching of the ancient Chinese philosophy through dialogue on science and religion, therefore to reduce the social instability and turbulence to ensure our endeavor in forming a harmonic and peaceful culture.

\section{Culture Difference Illuminated by Discussion on Gold and Jade [1-5]}

Gold and jade are well-known in the world as two economic important substances for their rarity, durability, monetary value, art value, as well as scientific study. Both have been considered as valuable and sought-after precious materials for art and jewelry long before recorded history. For gold, which is one of the least reactive chemical element, its usage as a standard for monetary policy is highly preferred between and within nations till the mid of last century. For jade, especially in China, it is highly valued and preferred for usage from ceremony, utilitarian to burial, as well as for artistic crafting . Below author would like to discuss the two substances from the aspect of their physical and chemical properties, for the purpose to show their impact to culture shaping and developing, and therefore to illuminate the culture difference between China and the West.

The general, physical and chemical properties of gold and jade are listed in the below tables. Certainly the properties listed here are not exhausted and only for discussion interested here.

Table1. Properties of gold $[2,4]$

\begin{tabular}{|c|c|}
\hline Symbol & $\mathrm{Au}$ \\
\hline Atomic numbers & 79 \\
\hline Phase & solid \\
\hline Appearance(color) & metallic, yellow with slightly reddish \\
\hline Density (r.t.) ${ }^{\mathrm{a}}$ & $19.30\left[\mathrm{~g} / \mathrm{cm}^{3}\right]$ \\
\hline Melting point & $1064.18\left[{ }^{\circ} \mathrm{C}\right]$ \\
\hline Boiling point & $2970\left[{ }^{\circ} \mathrm{C}\right]$ \\
\hline Atomic raius & $1.44[\AA]$ \\
\hline Crystal structure & cubic system, F.C.C., \\
\hline Ionization energy & $1^{\text {st: }}: 890.1[\mathrm{KJ} / \mathrm{mol}] ; 2^{\text {nd }}: 1980[\mathrm{KJ} / \mathrm{mol}]$ \\
\hline Electrical resistance & $22.14[\mathrm{n} \Omega \cdot \mathrm{m}]$ \\
\hline Heat capacity & $\begin{array}{l}25.418[\mathrm{~J} / \mathrm{mol} \cdot \mathrm{K}] \\
31(\text { comparing to spinel as } 1)\end{array}$ \\
\hline Hardness & $2.5[\mathrm{mohs}]$ \\
\hline Yong's modulus & $79[\mathrm{Gpa}]$ \\
\hline
\end{tabular}

a. r.t for room temperature

As we can see in Table 1, gold as a noble element metal is very dense and ductile, comparing to iron with density $7.874\left[\mathrm{~g} / \mathrm{cm}^{3}\right]$ (r.t.) and Yong's modulus 211 [Gpa]. Gold is very inert and occurs in native form, it is unaffected by oxygen at any temperature and resists individual acids except regia (royal water) for it is not easy to let gold lose its outermost electrons as its ionization energy shows. With its high malleability, high conductivity of electricity and resistance to corrosion and most other chemical reactions, gold is used in corrosion resistant connectors in all types of computerized devices. Because of its softness, gold is easily made thin enough to become transparent, so that a 
gold foil can be made to reflect infrared light. As a good heat conductor, gold is very useful as infrared shields in visors of heat-resistant suits.

Being with copper $\left.{ }_{29} \mathrm{Cu}\right)$ and silver $\left.{ }_{47} \mathrm{Ag}\right)$ in the same column of periodic table, i.e. group 11, gold is far more preferred as prized materials for jewelry, art and economics for long history even before recorded in world-wide because of its ductility and inertness to chemical reaction.

While along with the long history of the usage of gold, another such kind of material is jade. It was not until the 19th century (1863) that a French mineralogist, Alexis Damour, classified jade into two groups, i.e. jadeite and nephrite, after he studied the jade items from China. Today jade is world-widely known as naturally occurring inorganic substance with definite composition and it is consisted by microcrystallines inter-clocking together. In Table 2 and 3, the properties of jadeite and nephrite interested here are listed.

Table 2. Properties of jadeite (from burma) $[2,4]$

\begin{tabular}{|l|l|}
\hline Category & pyroxene group \\
\hline Formular & $\begin{array}{l}\left.\mathrm{NaAl}_{[} \mathrm{Si}_{2} \mathrm{O}_{6}\right] \text { when pure (Jadeitite); usually } \\
\text { with impurities } \mathrm{Ca}, \mathrm{Mg}, \mathrm{Fe}, \mathrm{Cr} \text {. They are } \\
\text { omphacite, diophside, aegirine, and } \\
\text { aegirine-augite }\end{array}$ \\
\hline Crystal system & monoclinic \\
\hline Color & $\begin{array}{l}\text { white, apple-green, green, grey-green, red, } \\
\text { brown, violet and blue-violet }\end{array}$ \\
\hline Hardness & $6.5 \sim 7$ [mohs] \\
\hline Luster & glassy to waxy or greasy \\
\hline Specific grativity & $3.24 \sim 3.43\left[\right.$ g/cm $\left.{ }^{3}\right]$ \\
\hline Crystal habit & massive \\
\hline Texture & crystalloblastic, metasomatic, cataclastic \\
\hline Diaphaneity & translucent \\
\hline Refractive index & $1.654 \sim 1.673$ \\
\hline Bifringence & $0.013 \sim 0.020$ \\
\hline Tenacity & 8 (comparing to carbonado as 10) \\
\hline Cleavage & good on [110] \\
\hline Heat conductivity & $0.4 \sim 0.56$ (comparing to spinel as 1) \\
\hline
\end{tabular}

As modern crystallography science revealed, the fine and delicate texture of jade is determined by how the microcrystallines interlock and the size of these microcrystallines. For jade with fibroblastic texture, usually most nephrites and some high quality jadeites formed in this way, can show extraordinary delicacy and thus attractive luster. Because of the high hardness and tenacity, jade is proper to be carved and crafted with quartz and garnet sand, and its durability feature makes it highly preferred and favoured as prized materials for these kinds of usage in China, as comparable with the significance of precious gem-stones, such as diamond, ruby and sapphire in the West.

Although jade was found and mined elsewhere such as India, Korea, other southeast Asia areas, New Zealand, Mesoamerica and Canada, and even splendid jade artistic work sparkled there for example Maya, Chinese jade tradition is special and particular known in world-wide for its significance[5]. It is believed that China is the first nation 
where people utilized jade-wares in Neolithic age ten thousand-years before. For these ten thousand-years long, jade culture became intrinsic to Chinese people. Chinese imperial rulers and scholars used jade for utilitarian, ceremony, ritual and burial, and even medicine. Chinese artisans acquired wonderful skills and techniques to make jade items which could be prized much more exceeding that of gold and silver. Chinese rulers and nobles understood jade as like a reflection of the mighty universe and world and through jade as medium worshipped and revered godly supreme beings. Accordingly they compared human's attributes with jade's, and moralized themselves as seeing their own-self images in a mirror for keeping proper from outside. With the preference and understanding, Chinese developed a splendid culture with philosophy, literature, art, science and technology, and medicine which are considered significant to human civilization. For these reason jade to Chinese has a meaning more than a ornamental stone.

Table 3. Properties of Nephrite $[2,4]$

\begin{tabular}{|l|l|}
\hline Category & amphibole group \\
\hline Formular & $\begin{array}{l}\mathrm{Ca}_{2} \mathrm{Mg}_{5}\left[\mathrm{Si}_{4} \mathrm{O}_{11}\right]_{2}(\mathrm{OH})_{2} \text { (tremdite); } \\
\mathrm{Ca}_{2}(\mathrm{Mg}, \mathrm{Fe})_{5}\left[\mathrm{Si}_{4} \mathrm{O}_{11}\right]_{2}(\mathrm{OH})_{2} \text { (actinolite) } \\
\text { with some } \mathrm{Mg} \text { substituted by Fe at least } \\
10 \% ;\end{array}$ \\
\hline Crystal system & monoclinic \\
\hline Color & $\begin{array}{l}\text { white, white to green (light or dark), dark, } \\
\text { yellow, brown, and mottled color }\end{array}$ \\
\hline Hardness & $6 \sim 6.5[$ mohs $]$ \\
\hline Luster & glassy, waxy to greasy \\
\hline Specific grativity & $2.95\left[\mathrm{~g} / \mathrm{cm}{ }^{3}\right]$ \\
\hline Crystal habit & massive \\
\hline Texture & fibroblastic \\
\hline Diaphaneity & translucent to opaque \\
\hline Refractive index & $1.606 \sim 1.632$ \\
\hline Bifringence & usually not detectable \\
\hline Tenacity & 9 (comparing to carbonado as 10) \\
\hline Cleavage & good \\
\hline Heat conductivity & low, no data, similar to jadeite \\
\hline
\end{tabular}

What we see and what we reflect. Likewise in the West a gold tradition and a gem-stone tradition formed since gold was found in native form and quartz can be easily obtained for its abundance in the Earth's continental crust. Long from Antiquity varieties of quartz have been commonly used in the making of jewelry and hard-stone carvings, especially in Europe and Middle East. In 17th century, Danish scientist Nicolas Steno found the first law of crystallography when he studied the properties of quartz. Steno's seminal work paved the way for study and denotation of crystal structure which forms the basis of crystallography. As a science, modern crystallography is a key basis of later semiconductor technology in the modern electronic industry. As gold tradition continues for jewelry, single crystals considered as precious gem-stones, such as ruby, sapphire and diamond, and semi-precious gem-stones cut to form subtle facets and mounted in gold are highly prized and valued for collection. Gemology is developed to make the profession into a science so that as 
jewelry any gem-stone in the market is certificated and science of gem-stones is studied in college. Beside this tradition gold is constantly used as a symbol for good and great, and associated with perfect or divine principles and wisdom of aging and fruition, which embodied the common wisdom of mankind.

As a summary, Chinese jade tradition is very special and exceptional, which reflects how Chinese ancestors understood world and universe philosophically. Below I will introduce some bases of this briefly and discuss the developing of modern Chinese culture.

\section{Discussion on Chinese Culture Developing [2, 6-9]}

As Chinese ancestors reflected world and universe through jade, and they understood and cultivated themselves as human beings with jade as a medium to compare with, Chinese philosophy is particular and exceptional, and so on the jade tradition became intrinsic to Chinese generations. The unusual thoughts were argued typically by the philosophic work as known as Taoism, such as Huangdi YinFu classics[6], Laozi [7] and Zhuangzi [8], and practiced by the world-wide known Saint Confucius who is the founder of Confucianism.

Among the greatest thinkers in Chinese long civilization history, Huangdi YinFu classics is highly admired till today by scholars. Together with the mysterious author, two other ancient important contributors to Taoism are LaoDan (not well known) and ZhuangZhou ( 369BC-286BC). In the later generations who followed Taoism, they retreated into themselves from public as known as recluses performing alchemy to find the way to become immortal. In another way as followed by many as known as confucianists they practiced and wished improvement to keep on the right so that as a saint or a follower to be helpful. With no doubting, Taoism and Confucianism are the two main wide-influenced philosophic theories among Chinese generation by generation, together with the well-known Buddhism from India in a form, strict or loose, as religion for people to be enlightened. So forth Taoism, Confucianism and Buddhism are in short labeled as the landmarks of Chinese culture. As understood, what the three landmarks argued and persuaded is a peaceful, harmonic and conflict-avoided living, and the difference among them is to achieve it by their very own way.

Nevertheless what is remarkably impressive, as the contributors of Taoism mentioned above showed, is that the contributors are not only genius among us, but also a figure who came with the knowledge already with him and a figure who was admired and doubted because of less understanding. However Taoism is certainly a legacy to Chinese descendants as well as to mankind under globalization in modern age. It can be seen that Huangdi YinFu classics can be only realized and cannot be argued, while readers can certainly understand what the basis logical end that Laozi argued. What Laozi introduced at the very beginning of his work, i.e. chapter 2 of DaoDe script (also known as Laozi), is that the existence of absolute accompanied by relative. By the logic, we have long and short, high and low, beautiful and ugly, good and evil. With this as basis, a saint will not provoke, but in a way lead harmony and peace, so that everything are naturally effective and keep in harmony for long. Certainly the way to achieve this ideal end is desirous and would be pursued with endeavor for right. Thus he introduced Dao to understand the way and De to acquire the understanding on the way. The later contributor Zhuangzi debated and deepened the principles in various typical aspects. He stated what the highest cultivated man for truth would be in a whole chapter. 
On the basis of the principle logic as Laozi argued, all things in the world exist and last to their end as by a Law living which is independent and exists before the world, and such living cannot be understood by human as be named or described, and so forth he used Dao to write it as a character, and defined its meaning to be big and as big as if you understand it in the opposite because it is too big to be observed. Once a thing exists by Dao, it has given attributes as being cultivated as it lasts. Laozi named De as it fulfills the function of the cultivation of the attributes of all things in the world. Hence Dao and De cannot be commanded, but exist there lasting naturally, which do but do not claim ownership, work but do not dominate, so as unknown as abstrusely profound and influential.

In a summary to understand the two essential concepts Dao and De in DaoDe script, as author understand, in chapter 51 Laozi revealed Dao and De and how all things in the world exist, and in chapter 25 Dao is introduced to clarify the beginning statement of the script in chapter 1 . The center ideology of conduction in human society for right is argued in chapter 38 to understand human ethics, and furthermore in chapter 70 Laozi emphasized his principle of saint and in chapters 77to 81 , he highlighted his ideology as an end. All through the short script Laozi revealed the hidden logical principle which is overlooked in the living life of mankind, and persuaded a harmonic, peaceful and conflict-avoided living for long and for right by introducing two profound concepts Dao and De and his philosophic principles and ideology by his arguments.

Today the modern Chinese life is being developed by advocate of western science and technology in all aspects. The principles of value and virtue are developing and even changing and forming. With the value of science adapted and accepted world-widely, China also faces the complexity and unknown of science, and problems such like that. By the history of science, what people are so convinced by science is the advance technology of electronics and that people's lives are improved and secured in all aspects as felt. Therefore all mankind work together to face any situations that science will bring to. In China as an ancient nation with its particular and exceptional culture, the ideal and idea of harmony and peace will always be a pursuit and a task for Chinese people. In this aspect Taoism is certainly worthy to be studied by scholars and be understood by young people together with Confucianism and Buddhism.

In modern age silicon single element crystal with high purity is the crucial material because of its usage in the integrate circuits in computers, and has a large impact on modern economy, although most amount of free silicon is used in other areas in industry. This economic important material rarely occurs as free pure element form in nature, but as various forms of silica and silicates, among which many are gem-stones used as jewelry-making, such as rock crystal, jade as mentioned above. Currently another widely studied material for new advantage in electronics is carbon. Comparing with silicon carbon is more basically important to our life. It is present in all forms of carbon-based life and is the chemical basis of all known life on Earth. It is the element which appears in most extraordinary variety of compounds, while under standard temperature and pressure, it is unreactive and resists except the strongest oxidizers. Today we know that carbon has allotropes as graphite, diamond, Buckminsterfullerene, carbon nanotube, graphene, and amorphous carbon. All carbon allotropes are solids, and graphite is the most thermodynamically stable form. Diamond is precious gem-stone which is the hardest substance in the world. Because of high cost, it does not have any major applications in industry. Graphene is extensively studied these years for its promising variety of applications in microelectronics. Science and technology of 
synthetic graphene based systems with graphene properties well controlled is considered promising and will have a large impact on economics in the future.

As we can see mankind living benefits from silicon and carbon largely and variously. Both of them can appear as gem-stones for jewelry-making usage, and they are also crucial materials in various areas in industry. This common feature means an important fact to us, as that value and virtue are so important and crucial to mankind, and our living depends on the right understanding of these and behaving right.

\section{Conclusion}

In summary by reviewing and comparing the properties of gold and jade, as well as the tradition of their usage in the West and China, the importance of silicon and carbon to mankind life is highlighted as that it should be understood not only from scientific view as crucial materials to industry and economics, but also as inspiration and enlightenment for reflection of humanity from the view of their usage of jewelry-making and treasure value because of the beauty and elegance, which make them gifts from nature in the forms of gem-stones to mankind.

What we see and what we reflect. This means that oversight and ignorance will certainly bring mankind inequity and conflict. To pursue and advocate a harmonic and peaceful cultivated living is surely a task for mankind. In the modern age with advantages being brought to us by advance electronics science and technology, the understanding of the essence of quantum phenomena is crucial and will continue to be studied profoundly.

\section{References}

[1] P. Patti, Collecting rocks, gems and minerals, 2nd ed., Krause Publications, 2012.

[2] Information on http://www.wikipedia.org

[3] Information on http://www.gemstones.org

[4] Peili Zhang, Systematic gemology, 2nd ed., geological publishing house, 2006.(In Chinese)

[5] Ming Yu, Chinese jade items, 1st ed., Five-continent media publishing house, 2008.(In Chinese)

[6] Huangdi, Huangdi YinFu classics-with critic of Bingyi Chang, 1st ed., Center translation publishing house, 2010.(In Chinese)

[7] Dan Lao, Laozi-with notes and interpretation by Guanglai Wei, 1st ed., Shanxi ancient-book publishing house, 2003. (In Chinese)

[8] Zhou Zhuang, Zhuangzi-with notes and interpretation by Junyan Wang and Yun Ji, 1st ed., Shanxi ancient-book publishing house, 2003.(In Chinese)

[9] P.Fara, Science-A four thousand year history, translated by Xinrong Huang, 1st ed., Center translation publishing house, 2011.(In Chinese) 